2016 Modular and Offsite Construction (MOC) Summit

Edmonton, Alberta, Canada, September 29 - October 01, 2016

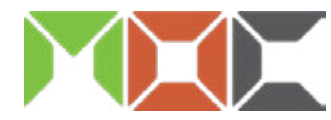

\title{
Polymer-based Modular Residential Building Design and Construction - A new Paradigm?
}

\author{
Andy $\mathrm{WONG}^{1}$, Pierre MERTINY ${ }^{2 *}$ \\ ${ }^{1}$ Undergraduate Student, Chemical Engineering, University of Alberta \\ ${ }^{2}$ Professor, Department of Mechanical Engineering, University of Alberta \\ *Corresponding author's e-mail: pmertiny@ualberta.ca
}

\begin{abstract}
The onsite wood frame method of constructing new buildings has been the norm for residential and basic commercial structures for more than a century. In this review study, we consider investment into plastic composite structures to supplement or replace wood frame home construction. Previous developments in this field often centralize on using a classic composite sandwich panel design: a polymer-based core material adjoined to layers of synthetic fiberreinforced polymer (e.g. fiberglass). The core of the composite panels is designed to meet demands toward low cost, light weight, and structural rigidity. Different varieties of plastics, including thermosets and thermoplastics, are discussed. Factors that need to be considered in the fabrication of composite modular residential buildings include, but are not limited to, energy consumption (both in building heating and cooling, and fabrication energy usage), fire resistance, resource use, environmental impact, human impact, and cost. Basic fabrication principles and techniques for composite modular panels are reviewed, wherein mechanical and electrical work can be incorporated into the building during panel manufacturing. Methods in which panels can be fabricated in high volumes that enable economies of scale are described. Thusly, recent progress in the application of plastics forming and machining that is applicable to the construction industry, and the feasibility of this type of residential construction are elucidated and discussed holistically.
\end{abstract}

\section{KEYWORDS}

Composite materials, composite building fabrication, modular construction, review study 


\section{INTRODUCTION}

Fiber-reinforced plastic (FRP) composites are used extensively in the automotive, aviation, marine, and construction industries. At home, consumer products like tools, toys, electronics, and sporting goods incorporate FRPs. Advances in composite manufacturing enable competitive cost production and high production volumes of high performance components. This paradigm can be applied to the offsite modular construction of residential and commercial buildings. The need for control over the surrounding environment and the necessity for complex machinery hampers on-site construction methods for composite structures, but with the transition to factory-based modular fabrication of buildings, 'plastic houses' are now a possibility.

In comparison to wooden, steel, and concrete structures, FRP composite houses offer substantial strength and are lightweight, thermally and electrically insulative, resistant to corrosion, mold growth and pests. In locales prone to flooding, earthquakes, hurricanes, and/or other natural disasters, FRPs do not fail catastrophically in a brittle manner like concrete, and are unaffected by moisture as opposed to wood and steel (American Composites Manufacturers Association, 2016). Moreover, polymeric materials for FRP composite houses can be derived from fossil hydrocarbon resources or biological sources using bioresins, which would create opportunities for value-added processing of natural resources and agricultural products in regions such as the Province of Alberta in Canada.

\section{MATERIAL SELECTION}

Using FRP composites in architecture is not a novel idea. Architectural marvels like the Stedelijk Museum of Modern Art and the San Francisco Museum of Modern Art, shown on the left and right hand side of Figure 1, respectively, demonstrate that not only can composites be used to build aesthetically stunning landmarks, but also meet stringent modern building and safety codes (CompositesWorld, 2016a).

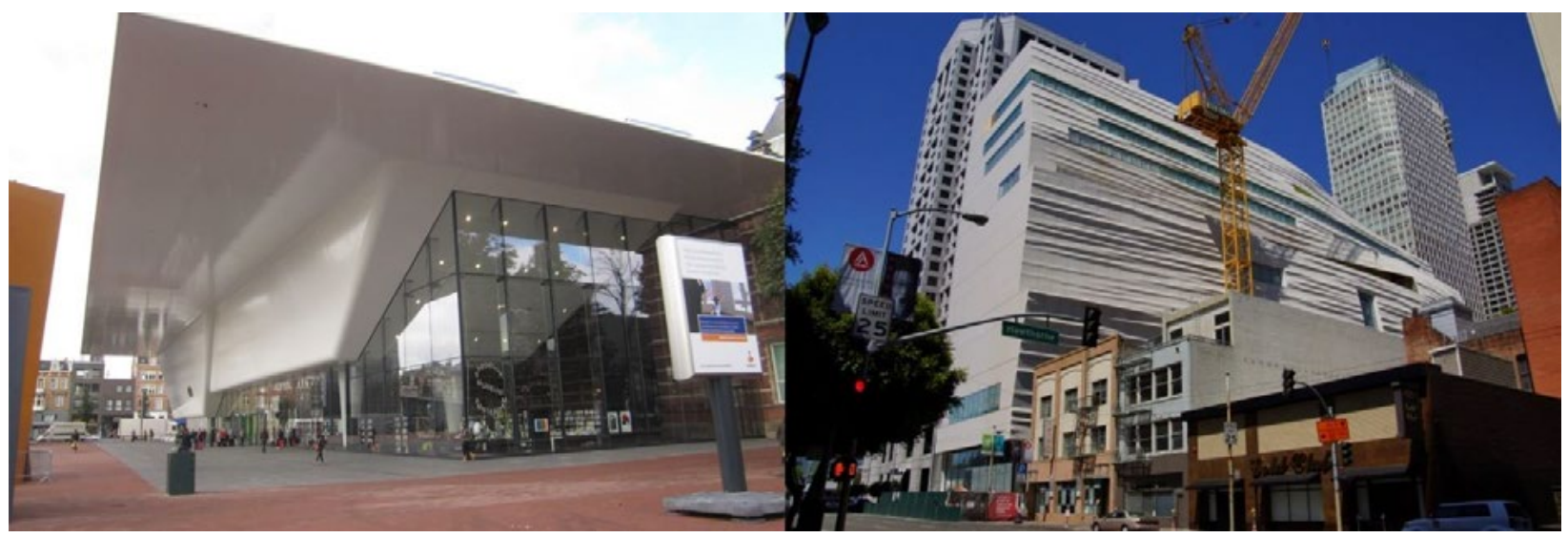

Figure 1. Left: Stedelijk Museum of Modern Art (Source: Wikimedia Commons); Right: San Francisco Museum of Modern Art (Source: Nicolas Janberg, Structurae) 
FRP composites are created by impregnating a fibrous material like glass fiber, aramid fiber or carbon fibers with a polymer resin, commonly a thermoset plastic (e.g. epoxies, unsaturated polyesters, vinyl esters). As the resin sets, the composite part can be shaped into its final form, where it solidifies. Thermoset plastics are inherently difficult to recycle due to the cross-linked polymer chain morphology, and can hardly be separated from the fiber matrix to be reused or recycled. In contrast, thermoplastics can more readily be melted and separated from the fiber reinforcement, provided they are not contaminated. (Zaman et al., 2014)

Companies using FRP composites in residential building construction already exist. Using pultruded fiberglass I-beams, Composite Building Structures Ltd. uses composite materials to replace 2"x 6" wooden members in traditional stick/frame construction (Stewart, 2011). Although the concept exhibits many benefits of composite construction, i.e. in durability, moisture and pest resistance, it fails to utilize and exploit geometry options and mechanical properties efficiently to maximize performance. There are several other companies invested in developing similar composite structural elements like composite posts, beams and columns. This dichotomy in thinking brings about the two possibilities when adapting FRP composites for use in construction: using traditional methods, developed for traditional materials (wood-based stick and frame construction, or reinforced concrete), or by developing modern and innovative designs which utilize the benefits of plastics fully. By changing the entire construction paradigm, and constructing both structural and non-structural elements with a composite sandwich panel, a potential exists for minimizing costs and maximizing performance. Composite sandwich panels are attractive in this context as they provide high performance at moderate costs. As seen in Figure 2, a sandwich panel consists of three major components: a core material, and two FRP laminate skins on either side of the panel. Innovative Composites International Ltd. (ICI) constructed economic and recyclable houses with thermoplastic sandwich panels. The target markets for these houses were impoverished communities in developing countries where durability and low costs were paramount (Stewart, 2011). The same concept can be applied further to modern home construction in economically developed countries, with focus on aesthetics, sustainability and minimizing the environmental impact, whilst adhering to other requirements in terms of safety and durability. ICI used polypropylene impregnated glass fibers over a foam core. The choice of the three main materials used to manufacture the sandwich panels is critical: polymer and fiber-reinforcement for the surface sheets, and the core material.

\section{Selection of fiber reinforcement}

Economical fiber choices are limited, shown in Table 1. The majority of FRP composites are made with glass fibers, of which so-called E-glass is most economical. Recyclable, biological materials are currently being researched for use in automotive manufacturing, both to strengthen plastics, and also as a substitute to glass fibers. Examples of these include flax, hemp, and coconut fiber, which have the advantage of being biodegradable, and could possibly be a viable source of fibers in the future (CompositesWorld, 2016b). Research into adapting these fibers to be used in structural components is ongoing (Burgueno et al., 2005). High performance choices include carbon fibers and aramid fibers (synthetic aromatic polyamides), among others. Currently, E-glass grade fiberglass is ideal for use in composite sandwich panels for residential applications due to its low cost to performance ratio, with natural plant fibers being a potential alternative. 


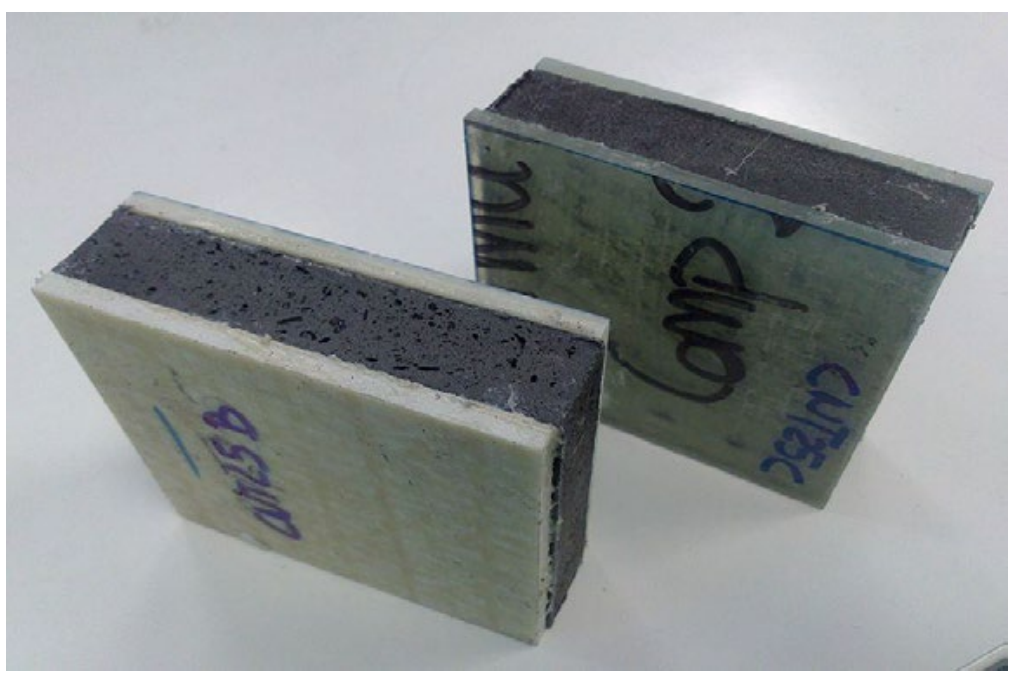

Figure 2. The three layers of a sandwich panel: a core material (e.g. foam) and two composite skins (Image source: Nanocore/Wikimedia Commons).

Fiberglass can be sourced in rovings (long continuous glass filaments, rolled up on a spool), which can be either woven into a sheet, or chopped up and used as a mat. Woven sheet glass fiber reinforced plastics (GFRP) exhibit the best strength, but reduced toughness (Thomason \& Vlug, 1996), whereas chopped fiber composites enable using more cost and volume-efficient layup techniques (Molded Fiber Glass Companies, 2016).

Table 1. Properties and cost per unit weight of various fibers (Data source: Wallenberger \& Bingham, 2009; Mohammed et al., 2015; and market research).

\begin{tabular}{llll}
\hline & $\begin{array}{l}\text { Elastic Modulus } \\
(\mathrm{GPa})\end{array}$ & $\begin{array}{l}\text { Tensile Strength } \\
(\mathrm{MPa})\end{array}$ & $\begin{array}{l}\text { Cost } \\
(\$ / \mathrm{lb})\end{array}$ \\
\hline $\begin{array}{l}\text { Fiberglass: } \\
\text { E-Glass }\end{array}$ & 72 & 3445 & $\$ 0.40$ \\
\hline $\begin{array}{l}\text { Bio-Fibers: } \\
\text { Hemp }\end{array}$ & 70 & $550-900$ & $\$ 1.40-\$ 1.80$ \\
\hline $\begin{array}{l}\text { High Performance: } \\
\text { Carbon (T700SC) }\end{array}$ & 230 & & \\
Aramid (K49) & 112 & 4900 & $\$ 20$ \\
\hline
\end{tabular}

\section{Polymer resin choices}

Resins, fiber type, fiber diameter, and any additives need to be compatible in order to have optimal mechanical performance in a FRP composite; as such, all the components need to be selected accordingly. Thermosets are generally brittle and difficult to recycle, with waste plastic disposed of in landfills or incinerated; both are environmentally questionable practices (Zaman et al. 2014). The major advantage of thermosets is the liquid state of the monomer resin phase prior to setting, allowing easy incorporation into the fiber matrix, where it subsequently polymerizes. Thermoplastics, on the other hand, exhibit high impact resistance, and can be extracted from FRP 
waste for reuse or recycling, but require more complex fabrication methods as the thermoplastic polymer needs to melted in order to incorporate it into the fiber reinforcement. The feed is usually in the form of thermoplastic pellets, powder, or a sheet type, all of which may have the fibers already incorporated into the plastic.

Polyethylene (low and high density), polypropylene, polyethylene terephthalate (PET), and PVC are some of the most produced thermoplastics globally, and are all potential candidates for creating FRP housing. Polypropylene and polyethylene are the most commonly used thermoplastic composite resins, due to their low melting points, good impact resistance, and safety (d'Hooghe \& Edwards, 2000). Using recycled plastics instead of virgin materials to construct houses is also a possibility, and would greatly curb the amount of plastics entering the world's landfills.

\section{Sandwich core material options}

FRP sandwich panels have typically been built with the following types of core materials: foams (open or closed cell structure), corrugated cores (like cardboard), and honeycombs. Research is ongoing with utilizing greener options such as pulverized plastic wastes set in a resin (ecoplasbrick, 2014), and developments for using bio-materials like balsa wood (Osei-Antwi et al. 2013). Sandwich panels provide high strength and stiffness in compressive loads normal to the laminar plane, in tensile loads parallel to the plane, and in most torsional loads. The flexural modulus and strength of sandwich panels is also high in comparison to its constituent materials, due to a strong outer skin; this makes them ideal for floors and roofs. In order to be suitable for creating houses, the panels need to be sufficiently strong in compressive loads parallel to the laminate plane (as in a load bearing wall), where buckling may cause the collapse and failure of the sandwich panel. There are primarily two possibilities for failure in a sandwich panel wall: delamination of the skin material, and shear failure of the core material (Roberts et al., 2002). The core material must be selected based on performance in both modes of failure.

An attractive candidate for the core material is an expanded, rigid foam made of the same (or similar) plastic as the resin in the skin material. The separation of air into discrete voids in the foam reduces internal convective heat transfer through the wall. Choosing a core material with similar properties as the skin resin promotes inherent resistance to delamination, and eases bonding techniques like thermal, ultrasonic, or solvent welding (Yousefpour et al., 2004). Likewise, recycling is made easier as the two plastics do not have to be separated prior to processing. Notably, thermoplastics have inherently low surface energy, leading to difficulties in bonding via adhesives (Grunewald et al., 2015). Thus, ensuring strong bonding between the core material and the skins of the panel, where the chemical structure and/or properties can be different, may be a significant challenge.

\section{Environmental and safety requirements}

Fire resistance is fundamental to building safety, and building codes are in development to include composite structures. Additives can be included in the manufacturing process which impart fire resistance through gas phase, endothermic and/or char forming flame retardants. The major hazard of burning plastics is not limited to their flammability, but more importantly, minimizing or preventing toxic gas emissions from thermal decomposition (Woolley \& Fardell, 1982), which is already a major concern due to the abundant use of plastics in furniture and other items in the household (e.g., clothing, flooring, appliances). Consequently, the subject of fire resistance and 
toxic gas emission is an ongoing area of research, and the resulting developments can be potentially transferred to make polymer based home construction safer for the case of fire.

Certain plastic compounds will outgas over their lifespan. For example, PVC products which have residual vinyl chloride monomers are known to be carcinogenic (Borrelli et al., 2005), and solvents used in the manufacture of other plastics may present health concerns as well (Halden, 2013). Paradoxically, certain highly effective flame retardants, such as halogenated flame retardants, are of particular concern in this context. Consequently, a considerable body of work is still required to provide high-performance plastics that mitigate potentially negative health effects, and ensure consumer confidence and acceptance.

Another area to be addressed is that plastics are generally prone to UV damage. For example, polyethylenes used in outdoor applications typically contain carbon black to absorb UV radiation and counteract degradation effects. For different plastics, specific additives may be needed to prevent degradation from exposure to sunlight; indications of failure include cracks or fissure in the plastic surface, crumbling, delamination of the surface from the core material, and discoloration of the plastic. FRP panels can be painted or coated (e.g. gel-coat), both of which can be engineered to provide UV protection to the panel. Surface treatments may also impart additional fire and/or chemical resistance, and can all be implanted in the manufacturing process (American Composites Manufacturers Association, 2016).

\section{MANUFACTURING AND ASSEMBLY}

Composites may allow for unprecedented production rates in the context of modular building construction, especially if a high degree of automation is realized in the production. The feed materials are of consistent quality and geometry and can be provided continuously, leading to component production with limited downtime and wastage. Major developments have been made in the area of automation in composites manufacturing, including robotic machining and routering of foam polymer foam components, rapid precision cutting of fiber reinforcement fabrics, and subsequent polymer resin infusion and curing. Computer process control systems are available that integrate, monitor and manage the entire manufacturing process with its various production and machining stations.

\section{Component manufacturing processes}

While hand layup processes are ideal for prototyping, they lack the speed, repeatability and economy that automated manufacturing enables. Manual processes should therefore be reserved for delicate work that exceeds machine capabilities and parts assembly, which is inline with modern modular construction practices.

Composite panels and similar structures can be formed using molding processes, using molds and forming presses for part consolidation. Fiber reinforced plastic laminates can be stacked and foam cores be included, if necessary, using manual labor or industrial robots.

Pultrusion/extrusion is a high throughput manufacturing process for FRP composite panels with constant cross-sectional dimensions. In this case, the feed materials encompass the three major constituents: (i) polymer resin in liquid, powder or pellet form depending on the polymer type; 
(ii) fiber reinforcement such as fabrics or fiber mats; and (iii) the core material which may be provided as sheet stock or produced in situ (Karlsson \& Astrom, 1997). While in-situ foaming requires more complex equipment, it may accommodate panel geometries that vary in thickness, and also ensures better skin-core bonding. A major advantage of using thermoplastic resins in pultrusion/extrusion processes is the rate at which the plastics can be solidified simply by cooling. Most thermosets need to react chemically at elevated temperatures over appreciable time spans. However, fast reacting thermoset options exist, e.g., polyurethane resins can be formulated to be highly reactive in order to solidify in a matter of seconds. Resin pre-impregnated fiber reinforcements, so-called prepregs may also be used; however, this form of feed material tends to be expensive compared to the onsite combination of the fiber reinforcement with the resin matrix. Depending to the polymer type, the fiber-reinforced skins can be bonded to the sandwich core via adhesives such as epoxies or thermally welded. Panel surfaces can be refined at the end of the pultrusion/extrusion process, where they can be painted and coated to required specifications, e.g. interior/exterior surface protection to enhance fire resistance or UV resistance.

\section{Composite part machining}

Composite components usually require trimming and cutting, especially in the case of pultrusion/extrusion parts, to form discrete panels and other structural components. This machining work can be accomplished manually or automatically, using e.g. CNC routers and milling machines, in which manner spaces for electrical boxes and cable routings, plumbing, and HVAC can be provided. Notably, hidden raceways inside of wall or floor panels may be cut in the foam core prior to lamination. Machines for the above machining processes are commonplace and readily available. Moreover, mills and routers can easily be appended to continuous manufacturing processes like pultrusion. By changing machining instructions in correspondence to desired part geometry and function, as well as to accommodate the feed rate in the case of continuous fabrication processes, broad opportunities exist for part diversity and customization without interrupting production.

\section{Component assembly}

Traditional mechanical fasteners are not well suited for composite components. Nails and screws do not have sufficiently contact area in composite skin sheets and foam cores. Moreover, nails and screws in the surface skin layers may create significant stress concentration, which may be problematic when sandwich skin layers carry significant tensile and flexural loads (Demelio et al., 2001). Therefore, adhesive bonding techniques (thermoset and thermoplastic) and fusion joining of panels (thermoplastics) are apposite and cost-effective options. Note that the assembly of larger components can be aided using other plastic parts, such as the extruded joint components shown in Figure 3. Such additional components help with part alignment, and increase the available surface area for adhesive bonding and plastic fusion, or may even permit the use of mechanical fasteners. 

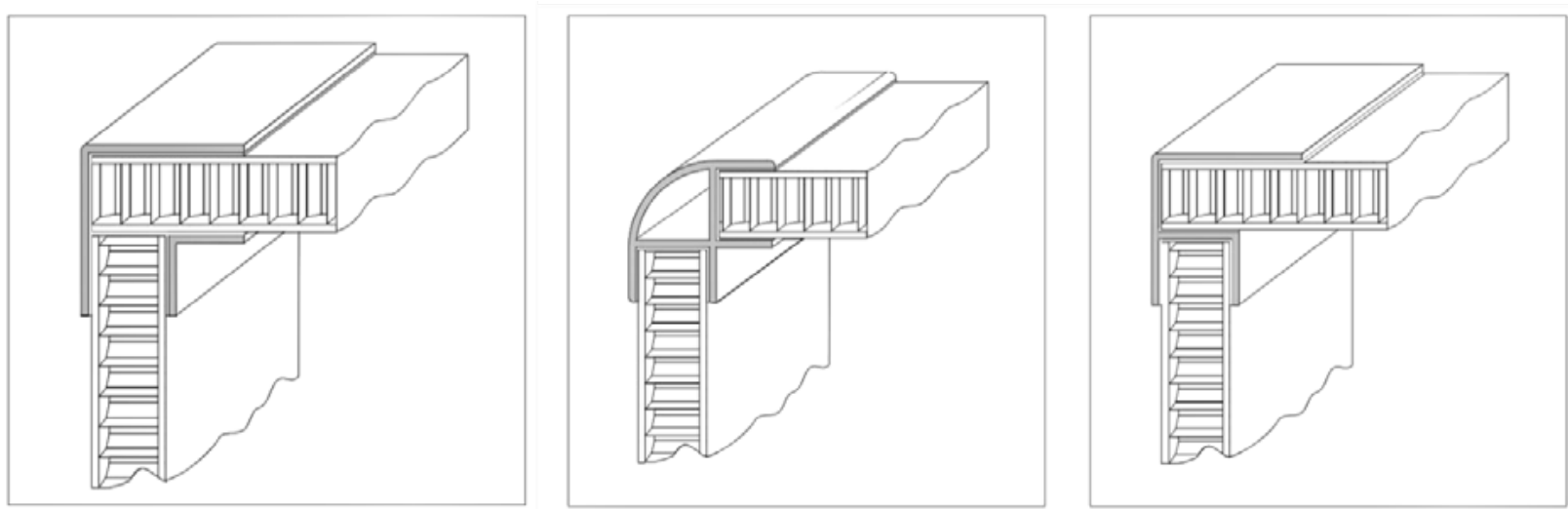

Figure 3. Extruded parts to increase corner strength (Image source: Hexcel Composites, 2001)

\section{CONCLUSIONS}

The adoption of composites by a broad range of industries has led to high performance material choices, expedient and cost-effective manufacturing, and structures with high durability and extended life cycles. Early examples indicate that the practices learned from these industries are transferable also to the housing industry. Plastic houses can be made in an environmentally friendly manner, focusing on minimizing the overall energy use by efficient production processes, reducing wastage while utilizing waste or sustainable material sources, and high energy efficiency of buildings. While safety concerns over fireproofing and effects on human health need to be appropriately addressed, plastics are already omnipresent in the modern world, and considerable efforts by industry and regulators steer future developments toward safer and healthier products. Now, with offsite construction being slowly adopted, composite construction may prove to be a more cost-effective and socially responsible option over traditional building practices. However, while the preceding review identified broad technological options for realizing plastic based houses, little information was found on the design of such structures, which is in its infancy, including aspect such as material selection, modularization, aesthetics, building climate, long-term performance and functionality. The latter refers to module compatibility and interchangeability to accommodate the building occupants' changing needs over time. Given these shortcomings, considerable efforts in research and development are required to realize the potentially significant benefits of plastic housing solutions.

\section{REFERENCES}

American Composites Manufacturers Association. (2016). http://compositeslab.com/. Borrelli, F.E., de la Cruz, P.L, and Paradis, R.A. (2005). "Residual Vinyl Chloride Levels in U.S. PVC Resins and Products: Historical Perspective and Update." Journal of Vinyl \& Additive Technology 11 (2): 65-69.

Burgueno, R., Quagliata, M.J., Mehta, G.M., Mohanty, A.K., Misra, M., and Drzal, L.T. (2005). "Sustainable cellular biocomposites from natural fibers and unsaturated polyester resin for housing panel applications." Journal of Polymers and the Environment 13 (2): 139-149.

CompositesWorld. (2016a). "The markets: Construction (2016)." http://www.compositesworld.com/articles/the-markets-construction-2016. 
CompositesWorld. (2016b). “The fiber (2016)." http://www.compositesworld.com/articles/thefiber-2016.

Demelio, G., Genovese, K., and Pappalettere, C. (2001). "An experimental investigation of static and fatigue behavior of sandwich composite panels joined by fasteners." Composites Part B 32: 299-308.

d'Hooghe, E.L., and Edwards, C.M. (2000). "Thermoplastic composite technology; Tougher than you think." Advanced Materials 12 (23): 1865-1868.

ecoplasbrick. (2014). "Ecoplasbrick at a glance - Layman's report." http://www.ecoplasbrick.eu/joomla/index.php/en/home.html.

Grunewald, J., Parlevliet, P., and Altstadt, V. (2015). "Manufacturing of thermoplastic composite sandwich structures: A review of literature." Journal of Thermoplastic Composite Materials 0892705715604681.

Halden, R.U. (2013). "Plastics and health risks." Annual Review Public Health 31: 179-194.

Hexcel Composites. (2001). "Sandwich Panel Fabrication Technology." http://www.hexcel.com/Resources/DataSheets/Brochure-Data-

Sheets/Sandwich Panel Fabrication Technology.pdf.

Karlsson, K.F., and Astrom, B.T. (1997). "Manufacturing and applications of structural sandwich components." Composites Part A 28: 97-111.

Mohammed, L., Ansari, M.N.M., Pua, G., Jawaid, M., and Islam, M.S. (2015). "A Review on natural fiber reinforced polymer composite and its applications." International Journal of Polymer Science 2015: 243947.

Molded Fiber Glass Companies. (2016). "Direct Long Fiber Thermoplastic Molding (D-LFT)." http://www.moldedfiberglass.com/processes/processes/closed-molding-processes/direct-longfiber-thermoplastic-molding.

Osei-Antwi, M., de Castro, J., Vassilopoulos, A.P., and Keller, T. (2013). "Shear mechanical characterization of balsa wood as core material of composite sandwich panels." Construction and Building Materials 41: 231-238.

Stewart, R. (2011). "Composites in construction advance in new directions." Reinforced Plastics 55 (5): 49-55.

Roberts, J.C., Boyle, M.P., Wienhold, P.D., and White, G.J. (2002). "Buckling, collapse and failure analysis of FRP sandwich panels." Composites Part B 33: 315-324.

Thomason, J.L., and Vlug, M.A. (1996). "Influence of fibre length and concentration on the properties of glass fibre-reinforced polypropylene: 1. Tensile and flexural modulus." Composites Part A 27: 477-484.

Wallenberger, F.T, and Bingham, P.A. (eds.) (2009). Fiberglass and Glass Technology: EnergyFriendly Compositions and Applications. Springer, New York, NY, USA.

Woolley, W.D., and Fardell, P.J. (1982). "Basic aspects of combustion toxicology." Fire Safety Journal 5: 29-48.

Yousefpour, A., Hojjati, M., and Immarigeon, J.-P. (2004). "Fusion bonding/welding of thermoplastic composites." Journal of Thermoplastic Composite Materials 17: 303-341.

Zaman, A., Gutub, S.A., Soliman, M.F., and Wafa, M.A. (2014). "Sustainability and human health issues pertinent to fibre reinforced polymer composites usage: A Review." Journal of Reinforced Plastics \& Composites 33 (11): 1069-1084. 